\title{
Avaliação nutricional da casca de soja com ou sem complexo enzimático na alimentação de leitões na fase inicial
}

\author{
Ivan Moreira ${ }^{1}$, Fábio Lima Mourinho², Paulo Levi de Oliveira Carvalho ${ }^{3}$, Diovani Paiano ${ }^{4}$, \\ Liliane Maria Piano ${ }^{5}$, Ilton Siguemi Kuroda Junior ${ }^{6}$
}

\footnotetext{
${ }^{1}$ Departamento de Zootecnia da Universidade Estadual de Maringá - DZO/UEM. Bolsista do CNPq.

2 Mestrando do Programa de Pós-graduação em Zootecnia da UEM. Bolsista da CAPES.

${ }^{3}$ Doutorando do Programa de Pós-graduação em Zootecnia da UEM. Bolsista da CAPES.

${ }^{4}$ Departamento de Zootecnia da UDESC, Chapecó, SC.

${ }^{5}$ Doutorando do Programa de Pós-graduação em Zootecnia da UEM. Bolsista do CNPq.

${ }^{6}$ Curso de graduação em Zootecnia da UEM. Bolsista PIBIC/CNPq/UEM.
}

RESUMO - Três experimentos foram conduzidos com o objetivo de avaliar o efeito da adição de complexo enzimático (CE) sobre o valor nutritivo da casca de soja utilizada na alimentação de suínos na fase inicial. O complexo enzimático utilizado continha $\alpha$-galactosidase, $\beta$-glucanase, galactomananase e xilanase. No experimento 1 , determinou-se a digestibilidade da casca de soja com complexo enzimático $(0,200$ e $300 \mathrm{mg} / \mathrm{kg})$ em leitões com peso inicial de 22,49 $\pm 1,73 \mathrm{~kg}$. Nenhum dos níveis de complexo enzimático afetou a digestibilidade da casca de soja. Assim, realizou-se outro ensaio de digestibilidade (experimento 2) com dois níveis ( 0 e $600 \mathrm{mg} / \mathrm{kg}$ ) de complexo enzimático e, novamente, a adição de complexo enzimático (600 mg de CE/ $\mathrm{kg}$ de ração) não melhorou a digestibilidade da casca de soja. No experimento para análise do desempenho (experimento 3), foram utilizados 60 leitões, machos castrados e fêmeas com peso inicial de 15,07 $\pm 1,69 \mathrm{~kg}$, distribuídos em delineamento em blocos casualizados, com cinco tratamentos, seis repetições e dois animais por unidade experimental. Avaliaram-se uma ração à base de milho e farelo de soja e outras quatro rações isonutritivas com $15 \%$ de casca de soja e complexo enzimático nos níveis $0,200,400$ ou $600 \mathrm{mg} / \mathrm{kg}$. O consumo diário de ração e o ganho de peso diário foram menores entre os animais alimentados com a ração contendo casca de soja em comparação àqueles alimentados com a ração-referência. Entretanto, a conversão alimentar melhorou de forma linear com inclusão do complexo enzimático $(200,400 \mathrm{e} 600 \mathrm{mg} / \mathrm{kg})$ O uso do complexo enzimático não afeta a digestibilidade da casca de soja, mas melhora a conversão alimentar de leitões $(15-30 \mathrm{~kg})$ alimentados com dietas contendo $15 \%$ de casca de soja.

Palavras-chave: alimento alternativo, desempenho, digestibilidade, enzimas, fibra, suínos

\section{Nutritional evaluation of soybean hull with or without enzymatic complex addition on starting pig feeding}

\begin{abstract}
Three experiments were carried out to evaluate the effect of adding enzymatic complex (EC) on the nutritive value of soybean hulls (SH) in starting pig feeding. The enzyme complex used contained $\alpha$-galactosidase, $\beta$-glucanase, galactomananase and xilanase. In experiment 1, the digestibility of soy bean hull with addition of enzyme complex was determined at three levels $(0,200$ and $300 \mathrm{mg} / \mathrm{kg})$, using piglets with initial body weight of $22.49 \pm 1.73 \mathrm{~kg}$. None of the enzyme complex levels affected the soy bean hull digestibility values. Therefore another digestibility trial (experiment 2) was conducted with two enzyme complex levels ( 0 and $600 \mathrm{mg} / \mathrm{kg}$ ). Adding enzyme complex (600 $\mathrm{mg}$ of EC/ $\mathrm{kg}$ of diet $)$ did not improve the soybean hull digestibility values. Sixty piglets were used in the performance trial (experiment 3 ), barrows and gilts, with $15.07 \pm 1.69 \mathrm{~kg}$ initial body weight, allotted to five treatments in a randomized complete design, with five treatments, six replications and two piglets per experimental unit. A corn and soybean meal based diet (BD) was assessed and a further four isonutritive diets with $15 \%$ soybean hull with the addition of increasing levels of enzyme complex $(0,200,400$ or $600 \mathrm{mg} / \mathrm{kg}$ ). Daily feed intake and daily weight gain were lower for the animals fed feed containing soybean hull compared to the control feed. However feed conversion improved linearly with enzyme complex inclusion (200, $400 \mathrm{or} 600 \mathrm{mg} / \mathrm{kg}$ ). The use of enzymatic complex did not affect soybean hull digestibility, but it improved the feed conversion of starting pigs $(15-30 \mathrm{~kg})$ fed on diets with $15 \%$ soybean hull.
\end{abstract}

Key Words: alternative feedstuff, digestibility, enzymes, fiber, performance, swine 


\section{Introdução}

O crescimento da suinocultura brasileira nos últimos anos (Roppa, 2006) eleva a demanda por alimentos utilizados na composição das rações. Do mesmo modo, a demanda por milho e farelo de soja, principais componentes das rações, tem se elevado por se tratar de duas commodities utilizadas no mundo todo. Assim, alternativas alimentares ao milho e farelo de soja são de grande interesse para a cadeia produtiva de carne suína.

No processamento para extração do óleo, têm-se como principais subprodutos o farelo de soja, de elevado teor proteico e de baixa concentração de fibra, e a casca de soja, película que reveste o grão. Obtém-se ainda o resíduo da limpeza da soja, que pode, em determinadas situações, ser incorporado à casca de soja. Segundo Restle et al. (2004), como a casca de soja representa 7 a $8 \%$ do peso do grão de soja, estima-se produção de 3,7 milhões de toneladas no Brasil.

A composição química e energética da casca de soja apresenta variação significativa, pois não há padrão nas indústrias de moagem de soja (Moreira et al., 2009). Além disso, a presença de maior ou menor quantidade de vagem, de resíduos de caule, de partes da planta e de outros resíduos pode contribuir para aumentar essas variações.

Há limitações para o uso da casca de soja na alimentação de leitões, tendo em vista a correlação negativa entre o nível de fibras e a digestibilidade de alguns nutrientes e o aumento de processos de fermentação no trato gastrintestinal (Dilger et al., 2004). A casca de soja possui em torno de 75\% de polissacarídeos não-amiláceos (PNA), 60\% deles insolúveis (Lo, 1989; Dilger et al., 2004), e suínos não possuem enzimas específicas para digerir esses PNA e oligossacarídeos (rafinose e estaquiose) (Kim \& Baker, 2003). Uma das soluções tem sido a utilização de enzimas exógenas para hidrolisar esses carboidratos.

Normalmente, as enzimas comerciais usadas como aditivos não contêm uma única enzima; ao contrário, são preparados enzimáticos com uma variedade delas (Ferket, 1993; Walsh et al., 1993), o que é desejável, uma vez que as rações são compostas por vários ingredientes (Campbell \& Bedford, 1992). O uso de complexos enzimáticos contendo $\alpha$-galactosidase permitiria aos nutricionistas formular rações considerando o nível energético adicional (Cleóphas et al., 1995), que, segundo Bedford (1996), eliminaria os problemas causados pelos PNA, oligossacarídeos e fatores antinutricionais.

Assim, realizou-se este trabalho com o objetivo de avaliar o efeito da adição de complexo enzimático sobre o valor nutritivo da casca de soja utilizada na alimentação de suínos na fase inicial (15 a $30 \mathrm{~kg}$ ).

\section{Material e Métodos}

Foram conduzidos três experimentos na Fazenda Experimental de Iguatemi (FEI), pertencente ao Centro de Ciências Agrárias da Universidade Estadual de Maringá (CCA/UEM). A casca de soja foi obtida junto à Cooperativa Agroindustrial de Maringá - COCAMAR em 24 de outubro de 2005, na forma de casca de soja integral (a granel), denominada casca de soja suja, pois contém grãos de soja quebrados, pedaços de vagem e de caule (planta) e sementes de invasoras.

A casca de soja foi moída utilizando-se moinho martelo (28 martelos), movido por um motor de $20 \mathrm{CV}$ e $3.550 \mathrm{rpm} \mathrm{e}$ peneira com furos de $2,5 \mathrm{~mm}$.

Utilizou-se um complexo enzimático contendo $\alpha$-galactosidase $(35,000 \mathrm{U} / \mathrm{g}), \beta$-glucanase $(1.100,000 \mathrm{U} / \mathrm{g})$, galactomananase $(110,000 \mathrm{U} / \mathrm{g})$ e xilanase $(1.500,000 \mathrm{U} / \mathrm{g})$. Foram conduzidos três experimentos: no 1 e no 2, foram realizados ensaios de digestibilidade e no 3 , um ensaio de desempenho.

No experimento 1, utilizaram-se 12 suínos, híbridos comerciais, machos castrados, com peso inicial de 22,49 \pm $1,73 \mathrm{~kg}$, distribuídos em delineamento inteiramente casualizado com quatro tratamentos e três repetições. A casca de soja substituiu $25 \%$ da ração-referência, à base de milho e farelo de soja e sem complexo enzimático, nos dois ensaios de digestibilidade. O complexo enzimático foi adicionado nos níveis de 200 e $300 \mathrm{mg} / \mathrm{kg}$.

Os animais foram alojados em gaiolas de metabolismo semelhantes às descritas por Pekas (1968). O ensaio foi de 13 dias: 8 de adaptação às gaiolas, às dietas e ao manejo, seguidos de 5 dias de coleta de fezes.

A ração-referência foi formulada seguindo os níveis nutricionais sugeridos pelo NRC (1998) para atender às exigências nutricionais de suínos na fase inicial ( 15 a $30 \mathrm{~kg}$ ). A composição química e os valores energéticos dos alimentos foram baseados nas tabelas de Rostagno et al. (2005).

As rações foram fornecidas duas vezes ao dia: $55 \%$ às $8 \mathrm{~h} \mathrm{e} 45 \%$ às $16 \mathrm{~h} 30$. A quantidade diária foi preestabelecida de acordo com o consumo dos animais na fase de adaptação, com base no peso metabólico $\left(\mathrm{PV}^{0,75}\right)$ de cada unidade experimental. As rações foram umedecidas com aproximadamente $100 \mathrm{~mL}$ de água para evitar desperdícios, reduzir a pulverulência e facilitar o consumo. $\mathrm{O}$ fornecimento de água foi fixado em $2,7 \mathrm{~mL}$ por grama de ração, fornecida após as alimentações diárias nos próprios comedouros.

Utilizou-se o método de coleta total de fezes, com adição de $2 \%$ de óxido férrico $\left(\mathrm{Fe}_{2} \mathrm{O}_{3}\right)$ às rações como marcador do início e final do período de coleta. Os 
procedimentos gerais de manejo e alimentação dos animais, coleta e manipulação de fezes e urina foram semelhantes aos descritos por Fialho et al. (1979) e Moreira et al. (1994).

Como no experimento 1 não foi observada melhora na digestibilidade da casca de soja com adição de complexo enzimático, o que sugere insuficiência de enzima, foi conduzido outro ensaio de digestibilidade, semelhante ao anterior, utilizando $600 \mathrm{mg} / \mathrm{kg}$ de complexo enzimático. $\mathrm{O}$ aumento do nível de complexo enzimático foi proporcional ao da fibra dietética contida nas rações com casca de soja em comparação à ração-referência. Utilizaram-se 15 suínos, híbridos comerciais, machos castrados, com peso inicial de $22,36 \pm 2,29 \mathrm{~kg}$, distribuídos em delineamento inteiramente casualizado, com três rações: uma ração-referência e duas rações com complexo enzimático nos níveis de 0 ou $600 \mathrm{mg} / \mathrm{kg}$, cada um com cinco repetições e um animal por unidade experimental.

Os teores de energia bruta das rações, cascas e fezes foram determinados em bomba calorimétrica adiabática (Parr Instrument Co., 1984). As composições químicas dos alimentos, das rações e das fezes foram determinadas conforme metodologias descritas por Silva \& Queiroz (2002). A granulometria das cascas foi determinada segundo metodologia descrita por Zanotto \& Bellaver (1996) e a composição aminoacídica foi obtida por meio de HPLC.
Os coeficientes de digestibilidade e os valores dos nutrientes digestíveis foram calculados utilizando-se a fórmula proposta por Matterson et al. (1965).

Os coeficientes de digestibilidade dos alimentos avaliados nos dois ensaios de digestibilidade foram submetidos à análise de variância utilizando-se o programa SAEG (UFV, 1997) e as médias, comparadas pelo teste F, de acordo com o modelo: $\mathrm{Y}_{\mathrm{ij}}=\mu+\mathrm{T}_{\mathrm{i}}+$ eij, em que: $\mathrm{Y}_{\mathrm{ij}}=$ coeficientes de digestibilidade do animal $\mathrm{j}$ recebendo o tratamento $i ; \mu=$ constante associada a todas as observações; $\mathrm{T}_{\mathrm{i}}=$ efeito do tratamento $\mathrm{i}$, em que $\mathrm{i}=$ nível do complexo enzimático; $\mathrm{e}_{\mathrm{ij}}=$ erro aleatório associado a cada observação.

No experimento 3, realizou-se análise de desempenho utilizando-se 60 leitões, machos castrados e fêmeas, híbridos comerciais com peso inicial de 15,07 $\pm 1,69 \mathrm{~kg}$ e peso final de 29,85 $\pm 3,46 \mathrm{~kg}$, no período de abril a maio de 2006.

As rações experimentais (Tabela 1) foram calculadas para serem isoenergéticas, isolisínicas, isoproteicas, isocalcíticas e isofosfóricas, segundo os níveis nutricionais propostos pelo NRC (1998). O valor de energia digestível da casca de soja $(2.071 \mathrm{kcal} / \mathrm{kg})$ foi obtido anteriormente no experimento de digestibilidade (experimento 1). Avaliaram-se cinco rações: uma testemunha, à base de milho e farelo de soja, sem casca de soja, e quatro rações com $15 \%$ de casca de soja e complexo enzimático nos níveis $0,200,400$ ou $600 \mathrm{mg} / \mathrm{kg}$ de ração (Tabela 1).

Tabela 1 - Composição centesimal, energética e química das rações experimentais

\begin{tabular}{|c|c|c|c|c|c|}
\hline \multirow[t]{2}{*}{ Ingredientes, \% } & \multirow[t]{2}{*}{ Ração-referência } & \multicolumn{4}{|c|}{ Nível de complexo enzimático, $\mathrm{mg} / \mathrm{kg}$} \\
\hline & & 0 & 200 & 400 & 600 \\
\hline Milho & 69,910 & 52,722 & 52,702 & 52,682 & 52,662 \\
\hline Farelo de soja & 26,889 & 25,464 & 25,464 & 25,464 & 25,464 \\
\hline Casca de soja & - & 15,00 & 15,00 & 15,00 & 15,00 \\
\hline Óleo de soja & - & 3,850 & 3,850 & 3,850 & 3,850 \\
\hline Fosfato bicálcico & 1,352 & 1,322 & 1,322 & 1,322 & 1,322 \\
\hline Suplemento vitamínico + mineral $^{1}$ & 0,500 & 0,500 & 0,500 & 0,500 & 0,500 \\
\hline Calcário & 0,634 & 0,452 & 0,452 & 0,452 & 0,452 \\
\hline Sal comum & 0,400 & 0,400 & 0,400 & 0,400 & 0,400 \\
\hline L-lisina, $\mathrm{HCl}$ & 0,214 & 0,162 & 0,162 & 0,162 & 0,162 \\
\hline DL-metionina & 0,050 & 0,067 & 0,067 & 0,067 & 0,067 \\
\hline Complexo enzimático & - & - & 0,020 & 0,040 & 0,060 \\
\hline Promotor de crescimento ${ }^{2}$ & 0,050 & 0,050 & 0,050 & 0,050 & 0,050 \\
\hline Total & 100 & 100 & 100 & 100 & 100 \\
\hline Energia digestível ${ }^{3}, \mathrm{kcal} / \mathrm{kg}$ & 3.350 & 3.350 & 3.350 & 3.350 & 3.350 \\
\hline Proteína bruta ${ }^{4}, \%$ & 17,37 & 17,83 & 17,83 & 17,83 & 17,83 \\
\hline Lisina total ${ }^{3}, \%$ & 1,09 & 1,09 & 1,09 & 1,09 & 1,09 \\
\hline Fibra bruta ${ }^{4}, \%$ & 2,98 & 6,78 & 6,78 & 6,78 & 6,78 \\
\hline Fibra em detergente neutro 4 , \% & 12,08 & 17,49 & 17,49 & 17,49 & 17,49 \\
\hline Fibra em detergente ácido ${ }^{4}, \%$ & 4,63 & 9,71 & 9,71 & 9,71 & 9,71 \\
\hline Extrato etéreo ${ }^{4}, \%$ & 3,24 & 6,67 & 6,67 & 6,67 & 6,67 \\
\hline
\end{tabular}

${ }^{1}$ Suplemento vitamínico e mineral (conteúdo/kg de produto): vit. A - 2.000.000 UI; vit. D3 - 400.000 UI; vit. E - 5000 UI; vit. K3 - 400 mg; vit. B12 - 6000 mcg; vit. B2 - $1.200 \mathrm{mg}$; biotina - $20 \mathrm{~g}$; ácido pantotênico - $2.400 \mathrm{mg}$; ácido nicotínico $-6.000 \mathrm{mg}$; colina $-30 \mathrm{~g}$; antioxidante $-20.000 \mathrm{mg}$; vit. B1 - $400 \mathrm{mg}$; vit. B6 - $600 \mathrm{mg}$; acido fólico - $200 \mathrm{mg} ; \mathrm{Cu}-35 \mathrm{~g} ; \mathrm{Zn}-20 \mathrm{~g}$; Co - $200 \mathrm{mg} ; \mathrm{Mn}-8 \mathrm{~g} ; \mathrm{Fe}-20 \mathrm{~g}$; I $-300 \mathrm{mg}$; veículo q.s.p. -1.000 g.

${ }^{2}$ Lincomicina (30\%).

3 Valores calculados baseados em Rostagno et al. (2005);

${ }^{4}$ Valores determinados no LANA - UEM. 
O delineamento experimental foi o de blocos casualizados, com cinco rações, seis blocos e dois animais por baia, constituindo a unidade experimental. Os animais foram pesados no início e ao final do experimento e o consumo total de ração foi computado para cálculo do consumo diário de ração, do ganho diário de peso e da conversão alimentar.

Os preços dos ingredientes utilizados nas dietas experimentais foram: milho grão, $\mathrm{R} \$ 0,28 / \mathrm{kg}$; farelo de soja, R \$ 0,50/kg; casca de soja, R \$ 0,18 (36\% do valor do farelo de soja); óleo de soja, R $\$ 1,38 / \mathrm{kg}$; fosfato bicálcico, R\$ $1,54 / \mathrm{kg}$; calcário, R\$ 0,16/kg; sal comum, R\$ 0,40/kg; lincomicina, R\$17,00/kg; suplemento mineral e vitamínico inicial R\$ 4,91/kg; L-lisina, R\$ 7,12/kg; DL-metionina, $\mathrm{R} \$ 12,41 / \mathrm{kg}$; complexo enzimático, $\mathrm{R} \$ 9,13 / \mathrm{kg}$.

A viabilidade econômica da adição de complexo enzimático nas rações foi determinada pela relação custo de ração por quilograma de peso ganho (Yi), segundo Bellaver et al. (1985). Em seguida, foram calculados o índice de eficiência econômica e o índice de custo, proposto por Gomes et al. (1991). Os resultados foram submetidos à análise de regressão polinomial, utilizando o programa SAEG (UFV, 1997), de acordo com o seguinte modelo estatístico: $\mathrm{Y}_{\mathrm{ij}}=\mu+\mathrm{b}_{1}\left(\mathrm{~N}_{\mathrm{i}}-\mathrm{N}\right)+\mathrm{b}_{2}\left(\mathrm{~N}_{\mathrm{i}}-\mathrm{N}\right)+\mathrm{e}_{\mathrm{ijk}}$, em que: $\mathrm{Y}_{\mathrm{ij}}=$ valor observado das variáveis estudadas, relativo a cada unidade experimental $j$ recebendo o nível $i$ de complexo enzimático; $\mu=$ constante geral; $b_{1}=$ coeficiente de regressão linear do nível de complexo enzimático sobre a variável Y; $\mathrm{b}_{2}=$ coeficiente de regressão quadrática do nível de casca de soja sobre a variável $\mathrm{Y} ; \mathrm{N}_{\mathrm{i}}=$ níveis de complexo enzimático, em que $i=0,200,400$ e $600 \mathrm{mg}$ de CE/ $\mathrm{kg}$ de ração; $\mathrm{N}$ = nível médio de complexo enzimático nas rações; $\mathrm{e}_{\mathrm{ijk}}=$ erro aleatório associado a cada observação.

Foi utilizado o teste de Dunnett para comparar a ração testemunha a cada um dos níveis de complexo enzimático (0, 200, 400 e $600 \mathrm{mg}$ de CE/kg), segundo Sampaio (1998), utilizando-se o nível de significância, o quadrado médio do resíduo e o número de repetições, da análise de variância global dos dados.

\section{Resultados e Discussão}

Os teores de aminoácidos analisados na casca de soja (Tabela 2) foram superiores aos obtidos por Dilger et al. (2004), exceto para metionina, treonina, cistina, glicina e serina, cujos valores foram semelhantes. Essas diferenças podem estar relacionadas às quantidades de grãos de soja misturados à casca durante o processamento industrial.
Tabela 2 - Composição de aminoácidos da casca de soja, do farelo de soja e do milho (matéria natural)

\begin{tabular}{lccc}
\hline Aminoácido $^{1}, \%$ & Casca de soja & Farelo de soja & Milho \\
\hline Metionina & 0,180 & 0,616 & 0,143 \\
Cistina & 0,210 & 0,702 & 0,170 \\
Metionina + cistina & 0,390 & 1,315 & 0,312 \\
Lisina & 0,840 & 2,882 & 0,214 \\
Treonina & 0,480 & 1,809 & 0,251 \\
Triptofano & $0,140^{2}$ & 0,629 & 0,056 \\
Arginina & 0,770 & 3,468 & 0,340 \\
Isoleucina & 0,530 & 2,132 & 0,221 \\
Leucina & 0,850 & 3,567 & 0,816 \\
Valina & 0,650 & 2,223 & 0,334 \\
Histidina & 0,350 & 1,254 & 0,218 \\
Fenilalanina & 0,540 & 2,400 & 0,331 \\
Glicina & 0,880 & ND & ND \\
Serina & 0,670 & ND & ND \\
Prolina & 0,660 & ND & ND \\
Alanina & 0,640 & ND & ND \\
Ácido aspártico & 1,310 & ND & ND \\
Ácido glutâmico & 1,660 & ND & ND \\
\hline
\end{tabular}

${ }^{1}$ Valores obtidos por meio de HPLC; ${ }^{2}$ Valor de Rostagno et al. (2005). ND - valor não-determinado.

Os valores de matéria seca $(87,94 \%)$, energia bruta (3.632 kcal $/ \mathrm{kg})$, cinzas $(3,76 \%)$, cálcio $(0,44 \%)$ e fósforo $(0,14 \%)$ da casca de soja moída em peneira de $2,5 \mathrm{~mm}$ (Tabela 3) foram superiores aos encontrados por Gentilini \& Lima (1996), enquanto os de proteína bruta (13,17\%), extrato etéreo $(2,49 \%)$, fibra bruta $(34,50 \%)$ e da atividade ureática $(0,35)$ foram inferiores aos encontrados por esses autores. Por outro lado, foram inferiores aos observados por Quadros et al. (2007) ao estudarem a composição química da casca de soja moída $(2,5 \mathrm{~mm})$ de mesma origem que a utilizada neste estudo para MS (90,37\%), PB (15,69\%) e cinzas (5,75\%). Neste mesmo estudo os valores de cálcio $(0,52 \%)$, fósforo $(0,28 \%), \operatorname{FDN}(56,47 \%)$, $\operatorname{FDA}(42,09 \%)$ e atividade ureática $(0,22)$ foram semelhantes, enquanto os de energia bruta $(3.804 \mathrm{kcal} / \mathrm{kg})$ e fibra bruta $(30,44 \%)$ foram superiores.

Em comparação aos resultados obtidos por Moreira et al. (2009), que avaliaram a casca de soja de mesma procedência deste estudo, os valores foram semelhantes para energia bruta (3891 kcal/kg), FDN (57,34\%) e FDA (39,74\%) da casca de soja moída $(2,5 \mathrm{~mm})$.

A solubilidade da PB em KOH $(0,2 \%)$ da casca de soja ficou abaixo da faixa ideal (70 a $85 \%$ ) estabelecida por Araba \& Dale (1990) e Parsons (2000). O valor de 66,44\%, entretanto, foi próximo dos recomendados para uso comercial, uma vez que Parsons et al. (1991) consideram $60 \%$ de solubilidade como valor crítico.

A atividade ureática, uma medida indireta da presença de fatores antinutricionais da soja, foi de 0,2 para casca de soja (peneira $2,5 \mathrm{~mm}$ ), dentro da faixa considerada ideal $(0,05$ a 0,2$)$, de acordo com Parsons (2000). No Brasil, são 
Tabela 3 - Composição química e energética e diâmetro geométrico médio da casca de soja moída em peneira de $2,5 \mathrm{~mm}$ (matéria natural)

\begin{tabular}{lc}
\hline Item & Casca de soja \\
\hline Matéria seca, \% & 88,85 \\
Matéria orgânica, \% & 83,87 \\
Energia bruta, kcal/kg & 3.890 \\
Proteína bruta, \% & 13,11 \\
Solubilidade da proteína em KOH, \% & 66,44 \\
Atividade ureática & 0,20 \\
Cálcio total, \% & 0,52 \\
Fósforo total, \% & 0,29 \\
Matéria mineral, \% & 4,98 \\
Fibra bruta, \% & 33,09 \\
Fibra em detergente ácido, \% & 41,86 \\
Fibra em detergente neutro, \% & 55,94 \\
Extrato etéreo, \% & 2,19 \\
Diâmetro geométrico médio & 522 \\
\hline
\end{tabular}

recomendados valores de atividade ureática de 0,05 a 0,3 para o farelo de soja (MAPA, 1990).

Na literatura, existem poucos trabalhos com avaliação nutricional da casca de soja, tanto em ensaios de desempenho como de digestibilidade. Além disso, a casca de soja é um subproduto com composição físico-química muito variável. Assim, a comparação de resultados muitas vezes é pouco consistente, com teores de proteína bruta que variam de 9,2 a 18,7\% (Cole et al., 1999).

As condições de processamento dos subprodutos também podem resultar em grandes variações na composição dos alimentos (Albino \& Silva, 1996), pois a casca de soja pode conter desde grãos de soja quebrados até sementes de invasoras, em diferentes proporções. A composição da casca de soja pode variar de acordo com o processo utilizado na sua obtenção, a variedade de soja cultivada, a região e a época de colheita, a regulagem das colheitadeiras, o tipo de colheita e a quantidade de resíduos de limpeza da soja incorporada.

No experimento 1 (Tabela 4), as dietas contendo complexo enzimático (200 ou $300 \mathrm{mg} / \mathrm{kg}$ ) não apresentaram alteração $(\mathrm{P}>0,05)$ nos coeficientes de digestibilidade dos nutrientes da casca de soja.

Resposta semelhante à do experimento 1 foi observada no experimento 2 (Tabela 5), no qual os coeficientes de digestibilidade dos nutrientes da casca de soja não melhoraram $(\mathrm{P} \geq 0,05)$ com o uso do complexo enzimático, apesar de ter sido utilizado o triplo da concentração (600 $\mathrm{mg} / \mathrm{kg}$ ) de complexo enzimático recomendada $(200 \mathrm{mg} / \mathrm{kg})$.

Esses resultados não eram os esperados, pois o complexo enzimático utilizado é composto de $\alpha$-galactosidase, galactomananase, xilanase e $\beta$-glucanase, que promovem a hidrólise de polissacarídeos não-amiláceos solúveis, como os arabino-xilanos, $\beta$-glucanos, $\alpha$-galactosídeos e galactomananos, presentes na casca de soja, melhorando a ação das enzimas digestivas endógenas e aumentando a digestibilidade dos nutrientes, possivelmente porque a quantidade de polissacarídeos não-amiláceos da casca de soja é bem mais elevada que a do farelo de soja, alimento para o qual o complexo enzimático foi desenvolvido. Nesse sentido, seria necessária a adição de quantidades ainda mais elevadas de complexo enzimático que a utilizada $(600 \mathrm{mg} / \mathrm{kg})$.

Com base nos resultados de digestibilidade, não houve efeito $(\mathrm{P}>0,05)$ do complexo enzimático sobre os oligossacarídeos da casca de soja, uma vez que o valor da energia digestível da casca de soja não melhorou com a adição do complexo enzimático, mesmo no nível mais elevado $(600 \mathrm{mg} / \mathrm{kg})$.

Tabela 4 - Coeficientes de digestibilidade e nutrientes digestíveis da casca de soja ${ }^{1}$, com ou sem complexo enzimático, em leitões na fase inicial

\begin{tabular}{|c|c|c|c|c|c|}
\hline \multirow[t]{2}{*}{ Coeficiente de digestibilidade, $\% \mathrm{MN}$} & \multicolumn{3}{|c|}{ Complexo enzimático, $\mathrm{mg} / \mathrm{kg}$} & \multirow[b]{2}{*}{$\mathrm{CV}^{2}$} & \multirow[b]{2}{*}{$\mathrm{P}<$} \\
\hline & 0 & 200 & 300 & & \\
\hline \multicolumn{6}{|l|}{ Experimento 1} \\
\hline Matéria seca & 58,75 & 49,21 & 58,26 & 21,96 & NS \\
\hline Energia bruta & 53,23 & 44,28 & 55,85 & 24,21 & NS \\
\hline Fibra em detergente neutro & 47,69 & 36,48 & 38,82 & 33,25 & NS \\
\hline Fibra em detergente ácido & 63,04 & 43,44 & 52,07 & 25,91 & NS \\
\hline Matéria seca digestível, \% & 52,20 & 43,73 & 51,76 & - & - \\
\hline Proteína digestível, $\%$ & 7,06 & 2,92 & 5,88 & - & - \\
\hline Energia digestível, $\mathrm{kcal} / \mathrm{kg}$ & 2.071 & 1.723 & 2.173 & - & - \\
\hline Fibra em detergente neutro digestível, \% & 26,68 & 20,41 & 21,72 & - & - \\
\hline Fibra em detergente ácido digestível, \% & 26,39 & 18,18 & 21,80 & - & - \\
\hline Fibra bruta digestível, \% & 17,84 & 12,93 & 15,76 & - & - \\
\hline
\end{tabular}

${ }_{1}^{1}$ Composição da casca de soja: $88,85 \%$ de MS; $13,11 \%$ de PB; 33,09\% de FB; 55,94\% de FDN, 41,86\% de FDA e 3.890 kcal de EB/kg.

${ }^{2}$ Coeficiente de variação, NS = não-significativo $(\mathrm{P} \leq 0,05)$. 
O período de adaptação dos animais às rações em experimentos de digestibilidade utilizando alimentos fibrosos suplementados com enzimas exógenas para leitões provavelmente tenha que ser maior, tendo em vista a necessidade de adaptação da microbiota intestinal aos elevados níveis de fibra (Cowieson et al., 2006).

Do mesmo modo, a metodologia com $25 \%$ de casca de soja em substituição à ração-referência provavelmente não é adequada para avaliar a digestibilidade dos nutrientes desse ingrediente (Villamide, 1996). Apesar de os altos níveis de substituição (25\%), acima dos níveis práticos de inclusão (15\%) nas rações, fornecerem estimativas do valor nutritivo mais acuradas e com menor erro, também aumenta a probabilidade de interação entre os ingredientes testados e a ração basal. Portanto, é possível que a metodologia com níveis crescentes de substituição da ração-referência pelo alimento teste (casca de soja) seja mais adequada por ser um alimento com elevado nível de fibra (Villamide, 1996).

A utilização de enzimas exógenas em pequenas quantidades poderia interferir temporariamente nas secreções endógenas do animal (Kim et al., 2003; Cowieson et al., 2006). Cowieson et al. (2006), trabalhando com frangos de corte, sugeriram a possibilidade de interferência das enzimas exógenas nessas secreções, causando aumento das perdas endógenas (enzimas, sais biliares, microbiota intestinal), sobretudo em experimentos de curta duração com avaliação do valor nutricional de alimentos.

Kim et al. (2003), trabalhando com adição de complexo enzimático ( $\alpha$-1,6-galactosidase, $\beta$-1,4-mananase, $\beta$-1,4manosidase) em dietas à base de milho e farelo de soja, e não casca de soja, para leitões na fase inicial $(11,05 \mathrm{~kg})$, verificaram diminuição significativa da concentração de rafinose e estaquiose durante a passagem pelo intestino delgado com o uso dessas enzimas. Estudando o efeito do mesmo complexo enzimático sobre a digestibilidade de dietas à base de milho e farelo de soja para suínos, Kim et al. (2006) verificaram melhora na digestibilidade ileal da matéria seca e energia bruta com o nível de $0,05 \%$ de suplementação enzimática.

Assim, novos estudos deveriam ser conduzidos observando essas ponderações na formatação dos experimentos para melhorar a avaliação do valor nutricional da casca de soja, um alimeno fibroso.

No experimento 3 (Tabela 6), a adição de $15 \%$ de casca de soja às dietas, independentemente do nível de complexo enzimático, causou redução $(\mathrm{P}<0,05)$ no consumo diário de ração e no ganho diário de peso dos animais em comparação àqueles consumindo dieta sem casca de soja, mas não houve efeito $(\mathrm{P}>0,05)$ dos níveis de complexo enzimático sobre essas variáveis. A casca de soja, ao alterar as carcaterístias físicas e/ou químicas da ração, reduz o consumo de ração, o que reflete no ganho de peso. Além disso, a adição do complexo enzimático não foi eficiente para superar este problema.

A conversão alimentar melhorou de modo linear $(\mathrm{P}=0,03)$ com a inclusão do complexo enzimático, o que sugere melhor utilização dos nutrientes da casca de soja com a adição do complexo enzimático. Esse resultado pode estar relacionado à ação do complexo enzimático sobre os oligossacarídeos e PNA presentes na casca de soja e no farelo de soja, que reduzem o desempenho. Esse resultado foi semelhante aos obtidos por Kim et al. (2003), que trabalharam com adição de $0,10 \%$ de complexo enzimático ( $\alpha$-1,6-galactosidase, $\beta$-1,4-mananase, $\beta$-1,4-manosidase) em dietas à base de milho e farelo de soja para leitões com peso inicial médio de $11,05 \mathrm{~kg}$ durante um período

Tabela 5 - Coeficientes de digestibilidade e nutrientes digestíveis da casca de soja ${ }^{1}$ com ou sem complexo enzimático para leitões na fase inicial (na matéria natural) experimento 2

\begin{tabular}{|c|c|c|c|c|}
\hline \multirow[t]{2}{*}{ Coeficiente de digestibilidade, \% } & \multicolumn{2}{|c|}{ Complexo enzimático, $\mathrm{mg} / \mathrm{kg}$} & \multirow{2}{*}{$\begin{array}{l}\mathrm{CV}^{2} \\
(\%)\end{array}$} & \multirow[t]{2}{*}{$\mathrm{P}<$} \\
\hline & 0 & 600 & & \\
\hline Matéria seca & 52,75 & 44,34 & 15,94 & NS \\
\hline Proteína bruta & 66,18 & 58,98 & 17,49 & NS \\
\hline Energia bruta & 41,52 & 37,34 & 18,75 & NS \\
\hline Fibra em detergente neutro & 61,41 & 54,87 & 19,25 & NS \\
\hline Fibra em detergente ácido & 49,75 & 41,21 & 25,49 & NS \\
\hline Fibra bruta & 40,73 & 34,90 & 35,32 & NS \\
\hline \multicolumn{5}{|l|}{ Nutrientes digestíveis } \\
\hline Matéria seca digestível, \% & 46,87 & 39,40 & - & - \\
\hline Proteína digestível,\% & 8,67 & 7,73 & - & - \\
\hline Energia digestível, $\mathrm{kcal} / \mathrm{kg}$ & 1.615 & 1.453 & - & - \\
\hline Fibra em detergente neutro digestível, \% & 34,35 & 30,69 & - & - \\
\hline Fibra em detergente ácido digestível, \% & 20,82 & 17,25 & - & - \\
\hline Fibra bruta digestível, $\%$ & 13,48 & 11,55 & - & - \\
\hline
\end{tabular}

${ }^{1}$ Composição da casca de soja: $88,85 \%$ de MS; $13,11 \%$ de PB; 33,09\% de FB; $55,94 \%$ de FDN, $41,86 \%$ de FDA e 3.890 kcal de EB/kg; ${ }^{2}$ Coeficiente de variação. $\mathrm{NS}=$ não-significativo $(\mathrm{P} \leq 0,05)$. 
experimental de cinco semanas. Os autores também não observaram diferenças para o ganho de peso e consumo diário de ração. Por outro lado, Kim et al. (2006), utilizando complexo enzimático (composto por $\alpha$-1,6-galactosidase, $\beta$-1,4-mananase, $\beta$-1,4-manosidase), $0,05 \%$, para suínos com peso médio de $24,1 \mathrm{~kg}$, durante quatro semanas, não observaram efeito sobre o consumo de ração, o ganho de peso e a conversão alimentar. Contudo, esses mesmos autores, utilizando animais mais pesados, com peso médio inicial de $64,1 \mathrm{~kg}$, observaram melhora apenas para o ganho de peso.

Estudando o efeito da enzima $\alpha$-galactosidase em dietas contendo milho, cevada ervilha e farelo de soja para suínos, Baucells et al. (2000) observaram melhora na conversão alimentar, resultado semelhante ao observado por Kidd et al. (2001), que estudaram a suplementação com enzima $\alpha$-galactosidase de dietas à base de milho e farelo de soja para aves e encontraram melhora apenas na conversão alimentar.

Conforme a quantidade de casca de soja e de fibras aumentou nas dietas, foi necessário adicionar óleo de soja para mantê-las isoenergéticas, uma vez que a casca de soja é um ingrediente pobre em energia em comparação ao milho. Uma diferença entre os ingredientes das rações utilizadas nos ensaios de digestibilidade e desempenho é a presença do óleo de soja nas dietas com casca de soja para promover o balanço energético. A presença de gordura na dieta torna o esvaziamento gástrico mais lento, em virtude do reflexo no duodeno decorrente da presença de lipídios na luz intestinal
(Hunt \& Knox, 1968). Isso pode sugerir que o atraso no esvaziamento gástrico resultaria em taxa de passagem mais lenta pelo intestino delgado. Além disso, as gorduras podem aumentar a digestibilidade ileal de aminoácidos (Li \& Sauer, 1994), uma vez que o tempo requerido para digestão de proteína e/ou absorção de aminoácidos é um fator limitante. Esse maior tempo de trânsito pelo intestino delgado pode ter beneficiado também a ação das enzimas exógenas sobre o substrato e, com isso, melhorado a conversão alimentar.

O custo de ração por quilograma de suíno produzido com as rações com complexo enzimático nos níveis 0, 200 e $400 \mathrm{mg} / \mathrm{kg}$ foi maior $(\mathrm{P}<0,05)$ que o obtido com a raçãoreferência, sem casca de soja, entretanto, o da ração com $600 \mathrm{mg} / \mathrm{kg}$ foi semelhante $(\mathrm{P}>0,05)$ ao da ração-referência (Tabela 7). Assim, o uso de complexo enzimático no nível de $600 \mathrm{mg} / \mathrm{kg}$ pode resultar em mesmo custo de ração por quilograma de suíno produzido em comparação à ração à base de milho e farelo de soja, sem casca de soja. Essa melhor resposta pode ser reflexo da melhora na conversão alimentar (Tabela 6) da dieta contendo $15 \%$ de casca de soja e suplementada com complexo enzimático no nível de $600 \mathrm{mg} / \mathrm{kg}$.

Os resultados gerais deste trabalho sugerem necessidade de adaptações na metodologia de avaliação da digestibilidade de alimentos fibrosos com o uso de enzimas exógenas para viabilizar a avaliação exata do efeito desses aditivos sobre o aproveitamento de alguns nutrientes pelos animais jovens.

Tabela 6 - Desempenho de leitões na fase inicial alimentados com rações contendo casca de soja com ou sem complexo enzimático

\begin{tabular}{|c|c|c|c|c|c|c|c|c|}
\hline \multirow[t]{2}{*}{ Variável } & \multirow[t]{2}{*}{ Ração-referência } & \multicolumn{4}{|c|}{ Nível de complexo enzimático, $\mathrm{mg} / \mathrm{kg}$} & \multirow{2}{*}{$\begin{array}{l}\mathrm{CV}^{1} \\
(\%)\end{array}$} & \multicolumn{2}{|c|}{$\mathrm{P}<$} \\
\hline & & 0 & 200 & 400 & 600 & & Dun $^{2}$ & $\operatorname{Reg}^{3}$ \\
\hline Peso inicial, $\mathrm{kg}$ & 14,95 & 15,11 & 15,19 & 15,04 & 15,21 & - & - & - \\
\hline Peso final, $\mathrm{kg}$ & 32,52 & 27,68 & 30,01 & 29,35 & 29,67 & - & - & - \\
\hline Consumo diário de ração, $\mathrm{kg}$ & 1,288 & $0,983 *$ & $1,122 *$ & $1,081 *$ & $1,075^{*}$ & 7,50 & 0,05 & NS \\
\hline Ganho diário de peso, $\mathrm{kg}$ & 0,627 & $0,449 *$ & $0,529 *$ & $0,511 *$ & $0,521 *$ & 10,29 & 0,05 & NS \\
\hline Conversão alimentar & 2,05 & 2,19 & 2,12 & 2,11 & 2,06 & 4,45 & NS & $\mathrm{L}: 0,03$ \\
\hline
\end{tabular}

${ }^{1}$ Coeficiente de variação; ${ }^{2}$ Teste de Dunnett: * Valor diferente $(\mathrm{P}<0,05)$ em relação à testemunha; ${ }^{3}$ Análise de regressão: $\mathrm{L}=$ efeito linear: $\mathrm{CA}=2,194005$ - 0,00020915CE. $\mathrm{NS}=$ não-significativo $(\mathrm{P}>0,05)$.

Tabela 7 - Avaliação econômica das rações experimentais fornecidas a leitões na fase inicial

\begin{tabular}{|c|c|c|c|c|c|c|c|c|}
\hline \multirow[t]{2}{*}{ Variável } & \multirow[t]{2}{*}{ Ração-referência } & \multicolumn{4}{|c|}{ Nível de complexo enzimático, $\mathrm{mg} / \mathrm{kg}$} & \multirow{2}{*}{$\begin{array}{l}\mathrm{CV}^{2} \\
(\%)\end{array}$} & \multicolumn{2}{|c|}{$\mathrm{P}<$} \\
\hline & & 0 & 200 & 400 & 600 & & Dun $^{3}$ & $\operatorname{Reg}^{4}$ \\
\hline Custo da ração, $\mathrm{R} \$ / \mathrm{kg}$ & 0,409 & 0,432 & 0,433 & 0,435 & 0,437 & - & - & - \\
\hline Índice de eficiência econômica & 100 & 88,63 & 91,32 & 91,32 & 93,55 & - & - & - \\
\hline Índice de custo & 100 & 112,82 & 109,50 & 109,50 & 106,88 & - & - & - \\
\hline
\end{tabular}

${ }^{1}$ Coeficiente de variação; ${ }^{2} \mathrm{RT}=$ ração à base de milho e farelo de soja; ${ }^{3}$ Teste de Dunnett: ${ }^{4}$ Análise de regressão; ${ }^{*}$ Valor diferente (P<0,05) em relação à ração-referência $\mathrm{NS}=$ não-significativo $(\mathrm{P}>0,05)$. 


\section{Agradecimentos}

À COCAMAR, pela casca de soja fornecida; à Uniquímica, pelo fornecimento do complexo enzimático; e ao laboratório da Degussa, pelos aminogramas realizados.

\section{Conclusões}

A utilização de complexo enzimático composto por $\alpha$-galactosidase, $\beta$-glucanase, galactomananase e xilanase não afeta a digestibilidade da casca de soja, mas melhora a conversão alimentar de leitões (15 a $30 \mathrm{~kg}$ ) alimentados com dietas contendo $15 \%$ de casca de soja.

\section{Literatura Citada}

ALBINO, L.F.T.; SILVA, M.A. Valores nutritivos de alimentos para aves e suínos determinados no Brasil. In: SIMPOSIO INTERNACIONAL SOBRE EXIGENCIAS NUTRICIONAIS DE AVES E SUINOS, 1996, Viçosa, MG. Anais... Viçosa, MG: UFV, 1996, p.303-318.

ARABA, M.; DALE, N.M. Evaluation of protein solubility as an indicator of overprocessing soybean meal. Poultry Science, v.69, n.1, p.76-83, 1990.

BAUCELlS, F.; PEREZ, J.F.; MORAleS, J. et al. Effect of ágalactosidase supplementation of cereal-soya-bean-pea diets on the productive performances, digestibility and lower gut fermentation in growing and finishing pigs. Journal of Animal Science, v.71, p.157-164, 2000.

BEDFORD, M.R. La utilizacion eficaz del trigo en las dietas avícolas. Industria Avícola, v.96, p.22, 1996.

BELlAVER, C.; FIALHO, ET.; PROTAS, J.F.S. et al. Radícula de malte na alimentação de suínos em crescimento e terminação. Pesquisa Agropecuária Brasileira, v.20, n.8, p.969-974, 1985 .

CAMPBELL, G.L.; BEDFORD, M.R. enzymes applications for monogastric feed: A review. Canadian Journal Animal Science, v.72, n.3, p.449-466, 1992.

CLÉOPHAS, G.M.L.; HARTINGSVELDT, W.V.; SOMERS, W.A.C. et al. Enzymes can play an important role in poultry nutrition. World Poultry, v.11, n.4, p.12-15, 1995.

COLE, J.T.; FAHEY, G.C.; MERCHEN, N.R.J. et al. Soybean hulls as a dietary fiber sources for dogs. Journal of Animal Science, v.77, p.917-924, 1999.

COWIESON, A.J.; ACAMOVIC, T.; BEDFORD, M.R. Using the precision-feeding bioassay to determine the efficacy of exogenous enzymes - A new perspective. Animal Feed Science and Technology, v.129, p.149-158, 2006.

DILGER, R.N.; SANDS, J.S.; RAGLAND, D. et al. Digestibility of nitrogen and amino acids in soybean meal with added soyhulls. Journal of Animal Science, v.82, p.715-724, 2004.

FERKET, P.R. Pratical of feed enzymes for turkeys and broilers. The Journal of Applied Poultry Research, v.2, n.1, p.75-81, 1993.

FIALHO, E.T.; ROSTAGNO, H.S.; FONSECA, J.B. Efeito do peso vivo sobre o balanço energético e protéico de rações a base de milho e sorgo com diferentes conteúdos de tanino para suínos. Revista da Sociedade Brasileira de Zootecnia, v.8, n.3, p.386-397, 1979.

Gentilini, F.P.; LiMA, G.M.M. Análise microscópica e determinação da atividade ureática dos componentes do subproduto casca de soja. In: REUNIÃO ANUAL DA SOCIEDADE BRASILEIRA DE ZOOTECNIA, 33., 1996. Fortaleza. Anais... Fortaleza: SBZ, 1996. p.260-262.

GOMES, M.F.M.; BARbosA, H.P.; FIALhO, E.T. et al. Análise econômica da utilização do triguilho para suínos. EMBRAPA - Centro Nacional de Pesquisa de Suínos e Aves, 1991, p.1-2 (Comunicado Técnico, 179).

HUNT, J.N.; KNOX, M.T. A relationship between the chain length of fatty acids and slowing of gastric emptying. Journal. Physiology, v.194, p.237, 1968.

KIDD, M.T.; MORGAN, G.W.J.; ZUMWALT, C.D. á-Galactosidase enzyme supplementation to corn and soybean meal broiler diets. The Journal of Applied Poultry Research, v.10, p.186-193, 2001.

KIM, S.W.; BAKER, D.H. Use of enzyme supplements in pig diets based on soybean meal. Pig News and Information, v.24, n.3, p.91-96, 2003.

KIM, S.W.; KNABE, D.A.; HONG, K.J. et al. Use of carbohydrases in corn-soybean meal-based nursery diets. Journal of Animal Science, v.81, p.2496-2504, 2003.

KIM, S.W.; ZHANG, J.H; SOLTWEDEL, K.T. et al. Use of carbohydrases in corn-soybean meal based grower-finisher pig diets. Animal Research, v.55, p.563-578, 2006.

LI, S.; SAUER, W.C. The effect of dietary fat content on amino acid digestibility in young pigs. Journal of Animal Science, v.72, p.1737-1743, 1994.

LO, G.S. Nutricional and physical properties of dietary fiber from soybeans.. Cereal Foods World, v.34, p. 530-534, 1989.

MATTERSON, L.D.; POTTER, L.M.; STUTZ, M.W. et al. The metabolizable energy of feed ingredients for chickens. Storrs: University of Connecticut, Agricultural Experiment Station, Research Report, v.7, n.1, p.11-14, 1965.

MINISTÉRIO DA AGRICULTURA PECUÁRIA E ABASTECIMENTO - MAPA. Secretaria de Fiscalização Agropecuária. Portaria ${ }^{\circ} 007$ de 09 de novembro de 1988. Anexo que estabelece os padrões mínimos das diversas matérias primas empregadas na alimentação animal, Decreto $\mathrm{n}^{\circ} 99427,1 / 8 / 1990$.

MOREIRA, I.; ROSTAGNO, H.S.; COELHO, D.T. et al. Determinação dos coeficientes de digestibilidade, valores energéticos e índices de controle de qualidade do milho e soja integral processados pelo calor. Revista Brasileira de Zootecnia, v.23, p.916-929, 1994

MOREIRA, I.; KUTSCHENKO, M.; PAIANO, D. et al. Effects of different grinding levels (particle size) of soybean hull on starting pigs performance and digestibility. Brazilian Archives of Biology and Technology, v.52, n.5, p.1243-1252, 2009 .

NATIONAL RESEARCH COUNCIL - NRC. Nutrient requirements of swine. 10.ed. Washington. D.C.: National Academy of Science, 1998. 189p.

PARR INSTRUMENTS CO., MOLINE, I.E. Instructions for the 1241 and 1242 adiabatic calorimeters. Moline: 1984. 29p. (Parr Manual, 153).

PARSONS, C.M.; HASHIMOTO, K.; WEDEKIND, K.J. et al. Soybean protein solubility in potassium hydroxide: An in vitro test of in vivo protein quality. Journal of Animal Science, v.71, p.133-140, 1991.

PARSONS, C.M. Assessment of nutritional quality of soy products for animals. In: DRACKLEY, J.K. (Ed.). Soy in animal nutrition. Illinois: Federation of Animal Science Societies, 2000. p.90-105

PEKAS, J.C. Versatile swine laboratory apparatus for physiologic and metabolic studies. Journal of Animal Science, v.27, n.5, p.1303-1309, 1968.

QUADROS, A.R.B.; MOREIRA, I.; PAIANO, D. et al. Avaliação nutricional da casca de soja integral ou moída, ensilada ou não, 
para suínos em fase de crescimento. Acta Scientiarum Animal Science, v.29, n.3, p. 31-38, 2007.

RESTLE, J.; FATURI, C.; ALVES, D.C.F. et al. Substituição do grão de sorgo por casca de soja na dieta de novilhos terminados em confinamento. Revista Brasileira de Zootecnia, v.33, n.4, p.1009-1015, 2004.

ROPPA, L. Perspectivas da produção mundial de carnes, 2006 a 2030. Revista Pork World, n.34, p.16-27, 2006.

ROSTAGnO, H.S.; ALBINO, L.F.T.; DONZELE, J.L. et al. Tabelas brasileiras para aves e suínos - Composição de alimentos e exigências nutricionais. 2.ed. Viçosa, MG: Universidade Federal de Viçosa, 2005. 186p.

SAMPAIO, I.B.M. Estatística aplicada a experimentação animal. Belo Horizonte: Universidade Federal de Minas Gerais, 1998. $221 \mathrm{p}$.
SILVA, D.J.; QUEIROZ, A.C. Análise de alimentos: métodos químicos e biológicos. 2.ed. Viçosa, MG: Imprensa Universitária, 2002. 235p.

UNIVERSIDADE FEDERAL DE VIÇOSA - UFV. Sistema de análises estatísticas e genéticas - SAEG. Versão 7.1. Viçosa, MG: 1997. 150p. (Manual do usuário).

VILLAMIDE, M.J. Methods of energy evaluation of feed ingredients for rabbits and their accuracy. Animal Feed Science and Technology, v.57, p.211-223, 1996.

WALSH, G.A.; POWER, R.F.; HEADON, D.R. Enzymes in the animal feed industry. Trends in Biotechnology, v.11, n.10, p.946-957, 1993.

ZANOTTO, D.L.; BELLAVER, C.N. Métodos de determinação da granulometria de ingredientes para o uso em rações de suínos e aves. Concórdia: CNPSA-EMBRAPA, 1996. p.15. (Comunicado Técnico, 215). 